América sin nombre, n. ${ }^{\circ} 22$ (2017) 17-24

DOI 10.14198/AMESN.2017.22.01

ISSN: 1577.3442 / eISSN: 1989-9831

Fecha de recepción: 20/09/2017

Fecha de aceptación: 21/11/2017
Puede citar este artículo como:

Ferreira, Rocío. "Cuentos del postconflicto peruano: entre el dolor y la esperanza en Al fin de la batalla. Después del conflicto, la violencia y el terron. El cuento hispanoamericano del siglo XXI. Agustín Prado Alvarado (coordinador). América sin Nombre, 22 (2017): 17-24, DOI: 10.14198/ AMESN.2017.22.01

Link para este artículo: http://dx.doi.org/10.14198/AMESN.2017.221.01

\title{
Cuentos del postconflicto peruano: entre el dolor y la esperanza en Al fin de la batalla. Después del conflicto, la violencia y el terror
}

\author{
Stories of the Peruvian postconflict: \\ between pain and hope in Al fin de la batalla. \\ Después del conflicto, la violencia y el terror
}

\author{
Rocío FERREIRA* \\ Universidad DePaul
}

\author{
Masa \\ Al fin de la batalla, \\ y muerto el combatiente, vino hacia él un hombre \\ y le dijo: «No mueras, te amo tanto!» \\ Pero el cadáver ¡ay! siguió muriendo. \\ Se le acercaron dos y repitiéronle: \\ «No nos dejes! ¡Valor! ¡Vuelve a la vida!» \\ Pero el cadáver ¡ay! siguió muriendo.
}

Acudieron a él veinte, cien, mil, quinientos mil,

clamando: «Tánto amor, y no poder nada contra la muerte!»

Pero el cadáver ¡ay! siguió muriendo.

Le rodearon millones de individuos, con un ruego común: «QQuédate hermano!»

Pero el cadáver ¡ay! siguió muriendo.

\footnotetext{
* Rocío Ferreira obtuvo el doctorado en literatura latinoamericana y estudios de género en la Universidad de California en Berkeley y ahora es catedrática de literatura latinoamericana y Directora del Programa de Posgrado en el Departamento de Lenguas Modernas de la Universidad DePaul en Chicago. Trabaja en temas relacionados con la literatura latinoamericana de los siglos XIX, xx y xxI y teoría de género. Ha participado en numerosos congresos internacionales y ha publicado artículos de crítica en libros y revistas especializadas. En su libro Del Salón Literario a la Cocina ecléctica: mujeres, cultura y nación en el Perú decimonónico, examina las escrituras de mujeres durante el siglo xix y las producciones culturales que se desarrollaron más allá de la metrópolis limeña. En su proyecto de investigación actual titulado «Yuyanapaq/para recordar: Memoria, desplazamiento y violencia política en la cultura peruana contemporánea» estudia la configuración de la memoria y la subjetividad a partir de la literatura peruana reciente.
} 


\author{
Entonces, todos los hombres de la tierra \\ le rodearon; les vio el cadáver triste, emocionado; \\ incorporóse lentamente, \\ abrazó al primer hombre; echóse a andar... \\ - César Vallejo, España aparta de mí este cáliz, 1939 -
}

\title{
Resumen
}

En los cuentos de la antología Al fin de la batalla. Después del conflicto, la violencia y el terror (2015) analizamos la manera en que cada narradora visibiliza con la escritura de su relato casos y experiencias significativos de las violaciones a los derechos humanos que ocurrieron en el Perú. En el acto mismo de escribir sobre el tema, las narradoras se solidarizan e identifican con los sobrevivientes del trauma social que significó el conflicto interno armado peruano con sus políticas de exterminio de los sectores más vulnerables de la población: los indígenas, las mujeres, los niños y los pobres. Nos referimos a las vidas precarias que quedan sin derecho a la protección; es decir, los cuerpos impensables, abyectos, invisibles y que por lo tanto se consideran sacrificables. Las narradoras se resisten con la escritura al silencio, el mismo que oculta y borra del imaginario nacional las experiencias de aquellos que vivieron el trauma de uno u otro flanco de la trinchera. Más aún, el proyecto de publicación de Al fin de la batalla: Después del conflicto, la violencia y el terror es un intento por acabar con la indiferencia y buscar la empatía hacia ese «otro» y restituirlo al imaginario nacional.

Palabras clave: cuentos; posconflicto peruano; dolor; violencia; mujer; narradores

\begin{abstract}
In the stories of the anthology Al fin de la batalla. Después del conflicto, la violencia y el terror (2015) we analyze the way in which each narrator makes visible in the writing of their narrative cases and significant experiences of the human rights violations that occurred in Peru. In the very act of writing on the subject, the narrators sympathize and identify with the survivors of the social trauma regarding the internal armed conflict in Peru with its policies of extermination of the most vulnerable sectors of the population: indigenous people, women, children and the poor. We refer to the precarious lives that are left without the right to protection; that is, unthinkable bodies, abject, invisible and therefore considered sacrificial. The narrators resist writing with silence, the same that conceals and erases from the national imagination the experiences of those who lived the trauma of one or the other side of the trench. Moreover, the publication project of $\mathrm{Al}$ fin de la batalla. Después del conflicto, la violencia y el terror (2015) is an attempt to end the indifference and seek empathy for that "other» and restore it to the national imagination
\end{abstract}

Keywords: stories; postconflict Peruvian; pain; violence; women; storytellers

"Al fin de la batalla» es el primer verso del poema «Masa» de César Vallejo (1892-1938), perteneciente al corto pero intenso poemario España aparta de mi este cáliz publicado póstumamente en 1939, que da título a la colección de cuentos Al fin de la batalla. Después del conflicto, la violencia y el terror (2015) compilada por Ana María Vidal Carrasco, texto del que nos ocuparemos en este ensayo. España aparta de mi este cáliz recoge quince poemas que Vallejo escribió en 1937 a raíz de presenciar la Guerra Civil de Espańa y quedar impactado con las innumerables muertes ocasionadas de la forma más sangrienta. En "Masa," poema XII, Vallejo muestra su solidaridad con el dolor humano y se identifica con la angustia y el sufrimiento del hombre. El poema propone que, con el amor colectivo solidario, el hombre puede vencer a la muerte y optar por continuar con la vida. Es decir, hay la esperanza de un renacimiento. Para lograrlo, es necesario que la sociedad en juego se identifique fraternalmente con el dolor del «otro,» el hermano sufriente. Para trascender y lograr un cambio en la sociedad, entonces, es necesario combatir la indiferencia humana. Este mismo sentido de solidaridad con los damnificados de la Guerra Interna en el Perú (1980-2000) -70,000 muertos, 15,000 desaparecidos, 600,000 desplazados y 40,000 niños huérfanos- es la apuesta que propone la antología de cuentos Al fin de la batalla. Después del conflicto, la violencia y el terror (2015), preparada y organizada por Ana María Vidal Carrasco, abogada experta en temas de género, derechos humanos, derechos indígenas y políticas públicas. Dentro de este contexto, 
no es gratuito que Vidal Carrasco haya tomado el primer verso de "Masa» como título de la compilación. Por el contrario, al incorporar ese primer verso, abre un diálogo entre el poemario de César Vallejo y los siete cuentos que componen la antología, tanto como con el llamado que hizo la Comisión de la Verdad y Reconciliación (CVR) en su Informe final (2003). Dicho reporte estableció enjuiciar a los perpetradores de crímenes de lesa humanidad, por un lado, y por otro, encontrar la verdad de los hechos ocurridos y divulgarla para poder construir una memoria colectiva. En este sentido, el proyecto de Vidal Carrasco es una invitación a reflexionar colectivamente, desde la cultura, con el claro propósito de visibilizar las experiencias de todos aquellos que fueron afectados durante y después del conflicto interno armado peruano y crear una memoria como resistencia al olvido de este periodo disruptivo de la historia del Perú.

En su libro Memory Matters in Transitional Peru (2014), Margarita Saona estudia como ciertas formas de arte visual y memoriales que se crearon en respuesta al conflicto interno armado han contribuido a entender el pasado y, a través de la empatía qué estos generan, hacer posible que se incorpore el sufrimiento de los sujetos «otros» excluidos de la nación. En la introducción, basándose en las contribuciones de Salomon Lerner, explica cómo fue posible que se cometieran tantas atrocidades de manera sistemática a ciertos sectores de la población y que tales actos quedarán impunes. El argumento que presenta Saona, y que aquí parafraseo, es el siguiente. La CVR confirmó que las violaciones a los derechos humanos que cometieron Sendero Luminoso (SL), otras organizaciones subversivas como el Movimiento Revolucionario Túpac Amaru (MRTA) y las Fuerzas Armadas (FFAA) no fueron casos aislados de violencia (11). Al haberse cometido, en forma sistemática y generalizada, las ejecuciones masivas, las torturas, los abusos sexuales y otro tipo de atrocidades, estos constituyen crímenes contra la humanidad (11). Salomón Lerner explica que cometer estas atrocidades fue posible debido a que la cultura predominante de exclusión, discriminación y racismo en el Perú, consintió ver y pensar a aquellos que viven en un frágil estado de precariedad (los indígenas, los pobres, los campesinos, niños y mujeres) como sacrificables (11). Dada la indiferencia generalizada de la sociedad peruana, una de las metas centrales de la CVR fue representarle a todo el país lo que le pasó a las poblaciones más afectadas. En otras palabras, se vio necesario presentar las historias de las múltiples violencias acaecidas a cuerpos precarios durante el conflicto armado a toda la nación. El primer esfuerzo que se hizo fue armar una muestra fotográfica titulada Yuyanapaq. Para recordar, que se exhibió en Lima en agosto del 2003 justo antes de la publicación del reporte de la CVR (17). A través de una «narrativa visual» se buscaba reconstruir la historia de los años de violencia y hacerla de ese modo pública (17). Entonces, a partir de este momento surgieron varios proyectos visuales, performativos, escriturales que se erigieron para luchar contra la amnesia política. En este sentido, Al fin de la batalla. Después del conflicto, la violencia y el terror (2015), a diferencia de otros textos literarios que se han compilado sobre el tema, éste continúa la tarea que propuso la CVR de lograr, a través de una memoria colectiva, una «sanación» nacional.

En este contexto, Vidal Carrasco explica, que la finalidad del proyecto es, a través de la ficción, «retratar el periodo de postconflicto, aquel que empezó a vislumbrarse cuando los gritos y las muertes cesaron» (contra carátula). Además, en la «Introducción» del libro «Pero el cadáver ¡Ay! siguió muriendo,» que toma como título el cuarto verso del poema "Masa» de César Vallejo, Vidal Carrasco confirma lo dicho y nos advierte que: «Existe una necesidad de narrar lo vivido. Tuve la oportunidad de verlo de cerca en las audiencias públicas de la Comisión de la Verdad y Reconciliación, el anhelo de muchas personas de sentirse escuchadas, de contar las violaciones de las que fueron víctimas, de que se oiga su voz, la de sus hijas, hijos, hermanas, hermanos y tantos familiares. Hoy 35 años después de iniciada la violencia y ya en una etapa de supuesto postconflicto, aún no hemos curado del todo las heridas y persiste la urgencia por contar nuestras historias» (9). Asimismo, en el «Prólogo» del libro, María Eugenia Ulfe, trae a colación este mismo sentimiento y nos advierte que: «La propuesta final de la CVR de pensar nuestro presente desde la historia es importante porque en el contexto peruano nos obliga, de un lado, a abrir el debate hacia la textura racializada y de género de nuestras relaciones sociales. Y, de otro lado, a repensar que el tema de acceso a derechos aún se asume en términos de 'privilegios' y es percibido como 'logros' y 'reconocimiento'. Ahí es cuándo la memoria de la violencia se convierte en acción política-en aquello que nos recuerda que es importante zanjar con el pasado para avanzar como sociedad y crecer democráticamente-» (14). Sin duda, estamos frente a un texto que se ocupa de la tan necesaria tarea de construir una memoria colectiva de las experiencias 
traumáticas de sujetos de distintos grupos sociales, raciales, étnicos, de género, e ideológicos que fueron afectados por la violencia institucionalizada, como veremos.

Frente al pedido de Vidal Carrasco, cada una de las siete narradoras invitadas colaboró con un cuento especialmente escrito para la antología: Jennifer Thorndike con «La muerte tenía nuestros dedos,» Christiane Félip Vidal con «Cuando el río suena,» Nataly Villena con «La etapa del nido,» Ysa Navarro con «Caminos,» Karina Pacheco con «Voy a cantarte,» Claudia Salazar con «El grito» y Julia Wong con «Algunos infortunios de la mujer con el cabello rojo.» Este ejercicio de escritura de las narradoras, desde distintas miradas y temas, entonces, se realiza vis à vis con el proyecto de la compiladora de ir en contra del negacionismo generalizado (la elección de negar la realidad para evadir una verdad incómoda) y construir una memoria colectiva de los traumas que aún se viven en la etapa del postconflicto. Además, los cuentos elucidan las preocupaciones, los intereses y los estilos narrativos de cada una de las escritoras que, interesantemente, están, de alguna manera, mediatizados por una estrofa de un poema que habla del poder sanador de la mujer.

En efecto, la sección de los cuentos se abre con un epígrafe del poema «Sanación» de la poeta Victoria Guerrero Peirano, una de las voces poéticas más interesantes de la actualidad. No sólo porque su poesía cuestiona los códigos sociales patriarcales, sino además porque se encarga de hacer visibles las múltiples violencias a las que los cuerpos de las mujeres son sometidos. "Sanación" es un poema en prosa cuya voz poética habla en primera persona de un trauma, una experiencia muy cruda que violenta su propio cuerpo gestante. Éste, al estar fuera de control, expulsa despiadadamente sus fluidos («la corriente de mi orina amarillenta y rojiza. /...tanto líquido que se arroja sin remedio.»). Es el cuerpo desestructurado que metonímicamente refleja el estado de cosas de una época muy concreta: los años del conflicto interno armado peruano. El dolor, el desasosiego y la frustración que plasma la voz poética ante la violencia del «ritual de la pérdida» están presentes en todo el poema hasta el momento en que se produce un cambio esperanzador. La voz poética recobra la dignidad en la estrofa final del poema, el epígrafe de la antología, donde: «...Furtivamente, zumbando como un golpe cálido que atraviesa el mundo, aparece la diosa pequeñita de trenzas negras y con sus manos diminutas se asoma sobre mi vientre, extrae la máscara que lo cubre y con sus hermosos ojos negros sorprendidos me sana» (15). Estos versos de Guerrero Peirano hacen eco al mensaje que nos da Vallejo en su poema "Masa,» que ya hemos comentado. Es decir, plantea la necesidad de encontrar una presencia solidaria que ayude a cicatrizar esas heridas que persisten abiertas. Para Victoria Guerrero «la dignidad es la única posibilidad de resistencia del humillado» y ésta llega de las manos de un sujeto femenino.

Ahora bien, es en este marco general comentaremos en los cuentos de la antología Al fin de la batalla. Después del conflicto, la violencia y el terror (2015) la manera en que cada narradora visibiliza con la escritura de su relato casos y experiencias significativos de las violaciones a los derechos humanos que ocurrieron en el Perú. En el acto mismo de escribir sobre el tema, las narradoras se solidarizan e identifican con los sobrevivientes del trauma social que significó el conflicto interno armado peruano con sus políticas de exterminio de los sectores más vulnerables de la población: los indígenas, las mujeres, los niños y los pobres. Nos referimos a las vidas precarias que quedan sin derecho a la protección; es decir, los cuerpos impensables, abyectos, invisibles y que por lo tanto se consideran sacrificables (Butler). En Vida precaria. El poder del duelo y la violencia, Judith Butler expone que: «Hay formas de distribución de la vulnerabilidad, formas diferenciales de reparto que hacen que algunas poblaciones estén más expuestas que otras a una violencia arbitraria.» (14). Esta realidad se hace evidente en los planteamientos que hacen las siete narradoras.

Jennifer Thorndike y Claudia Jiménez relatan desde el punto de vista de mujeres en posiciones de poder, los vejámenes que cometieron contra sujetos vulnerables desde sus cargos oficiales y como representantes del aparato del Estado peruano. Las protagonistas de los cuentos, fueron las ejecutoras de crímenes focalizados en los cuerpos «sacrificables» de sujetos pobres.

El primer cuento de la colección, «La muerte tenía nuestros dedos,» de Jennifer Thorndike, se enfoca en la guerra que desató el segundo gobierno de Alberto Fujimori contra los derechos reproductivos de la mujer: el caso de las esterilizaciones forzadas. Thorndike, se ocupa de relatar crudamente una historia directamente relacionada con el Programa Nacional de Salud Reproductiva y Planificación Familiar (1996-2000) que, cómo bien informa Alejandra Ballón en Memorias del caso peruano de esterilización forzada (2014), "dio como resultado la esterilización forzada masiva de mujeres y también 
de hombres peruanos, en su mayoría pobres, indígenas y de reciente procedencia rural» ("Introducción» 27). A su vez, Christina Ewig ha demostrado en su estudio «La economía política de las esterilizaciones forzadas en el Perú,» "como la administración del entonces presidente Fujimori en el Perú promovió una política tradicional maltusiana de población; es decir, antinatalista, que ponía el desarrollo económico nacional por encima de los derechos humanos de mujeres y hombres» (Ballón 29). Esta campaña «reflejaba, ante todo, el uso instrumental de la mujer» (Ballón 29). Con estos datos recogidos y después de hacer una investigación exhaustiva de la corresponsabilidad de la institución médica, Thorndike escribe sobre el estigma y las muertes que causaron las descuidadas e inhumanas esterilizaciones forzadas que miles de mujeres campesinas quechua hablantes padecieron en manos de médicos que cumplían con las cuotas asignadas por dicho programa durante la administración de Fujimori. Escrito en primera persona, desde la perspectiva de una doctora cuyos dedos son capaces de mutilar los cuerpos precarios y por tanto sacrificables de las mujeres andinas, el relato entra magistralmente en la psiquis de la protagonista quien cuestiona entre cumplir el deber asignado de esterilizar quirúrgicamente sin tener acceso a los mínimos recursos indispensables para efectuarlos o actuar con ética profesional y humanidad. La autora cuestiona el rol de la ética médica detrás de los abusos que comenten al detallar que dichos procedimientos se practicaron sin el consentimiento de las mujeres, las que fueron forzadas a operarse en condiciones higiénicas y de infraestructura inapropiadas y sin el seguimiento postoperatorio adecuado. Pues, cómo explica Ballón «Los altos mandos del gobierno de Fujimori-o sea la presidencia y la oficina del primer ministro entendían la planificación familiar, una vez más, principalmente como una herramienta para el desarrollo económico prescindiendo de la atención y respeto legítimamente debido ora a la preservación de la salud ora a los derechos reproductivos» (30). Pese a que la protagonista del cuento siente culpa de saber que está mutilando a seres vulnerables e incluso produciendo sus muertes, nada la detiene porque lo que importa es cumplir con la cuota. Sin embargo, el cuento termina con una cierta justicia poética ya que al final, las mujeres lisiadas se empoderan y expulsan del pueblo al equipo médico encargado de hacer las esterilizaciones forzadas. Además, antes de desalojarlas, las campesinas marcan en la palma de la mano "con un cuchillo afilado" a las doctoras para que les queden los dedos atrofiados y no puedan volver a cortar ni a lesionar los cuerpos de otras mujeres indígenas pobres. Ambos grupos de mujeres quedan con un estigma permanente.

De otra manera, en el cuento «El grito,» Claudia Salazar Jiménez se enfoca en narrar, en tercera persona, la experiencia de una mujer que sufre de estrés postraumático, después de haber sido parte de una misión militar oficial durante el conflicto interno armado que la lleva a la zona del combate. La protagonista es una ex-miembro de las Fuerzas Armadas quien en el presente de la narración vive en el extranjero. Sin embargo, su vida cotidiana, que parece ser normal, está plagada de imágenes y recuerdos traumáticos de las despiadadas matanzas que cometió en el Perú; especialmente de la cruenta forma que torturó a una mujer y la manera sangrienta que mató a un sargento. Salazar Jiménez enfatiza la severidad del estrés postraumático y la dificultad que tienen los perpetradores de la violencia de reinsertarse en la sociedad. El tema de las mujeres que participaron en las FFAA es poco o nada discutido. Este cuento muestra otro tipo de violencia a considerar; esto es, la situación de los ex miembros del FFAA quienes, al no poder contar sus experiencias, no pueden buscar ayuda profesional y, por lo tanto, están obligados a vivir con el trauma.

En estos cuentos, tanto la doctora como la mujer militar han quedado marcadas y traumatizadas por las imágenes que las persiguen constantemente de los crímenes que cometieron. Estas mujeres, que no son consideradas como cuerpos sacrificables, tienen también la difícil tarea de sanar.

Por su parte, Ysa Navarro y Christiane Félip Vidal se ocupan de contar las historias de otras vidas precarias, me refiero a la de los miles de niños huérfanos que el conflicto interno armado dejó. Cada niño tiene su historia de dolor, carga a sus espaldas un trauma difícil de suturar, y, sin embargo, de una forma u otra tiene que reinsertarse en una sociedad que al considerarlo como vida sacrificable no lo acoge con solidaridad. Ambos cuentos están narrados desde la mirada del niño perjudicado y desplazado de su entorno.

El cuento «Cuando el río suena» de Félip Vidal, como dice el dicho popular «agua trae.» En este caso se refiere a la situación de los niños Asháninka que después de quedar huérfanos por la guerra fueron desplazados de sus comunidades. Muchos de ellos, como es el caso del protagonista del cuento, fueron puestos en albergues dirigidos por pastores extranjeros. En estas misiones, los pastores quienes no entienden ni el idioma ni la cultura de los 
nińos, buscan integrarlos a la sociedad mediante un proceso de occidentalización cultural que borra su identidad. No sólo les hablan en un idioma que no les pertenece, sino que además no reciben el apoyo necesario para sobrepasar el trauma de la pérdida de los padres y del desplazamiento de su comunidad. $\mathrm{Al}$ no recibir muestras de comprensión solidaria de su situación psicológica, los niños enmudecen y solo buscan escapar. En este cuento, Félip Vidal aborda la historia desde el interior del protagonista para mostrar el trauma ocasionado a los niños pobladores de la Amazonía peruana.

El cuento «Caminos» de Ysa Navarro se ocupa de narrar la experiencia traumática de una niña andina que queda abandonada a su suerte después de sobrevivir el trauma de haber sido violada sexualmente por miembros de las FFAA, los mismos que torturaron y mataron a su familia. Al quedar sola, después que su familia entera fue aniquilada y su casa quemada, tiene que desplazarse hacia la capital y buscarse la vida. La protagonista representa a los miles de nińas y adolescentes que tuvieron que huir de sus pueblos después de presenciar los asesinatos de sus familias y de vivir en carne propia las violaciones sexuales de las que fueron víctimas. Según el Informe Final, la mayoría de las víctimas de las violaciones sexuales tenían entre 10 y 29 años de edad, aunque había victimas más jóvenes aún (Informe Final 276). Una gran cantidad de jóvenes quedaron embarazadas a causa de las violaciones forzadas durante la guerra interna como es la historia de la protagonista del cuento de Navarro. De hecho, muchas jóvenes se vieron obligadas a abortar en secreto y de manera peligrosa porque en el Perú abortar es un acto ilegal. Navarro muestra la dificultad que estas jóvenes, a quienes la sociedad considera vidas precarias, tienen que afrontar solas después de haber sido violadas sexualmente, haber quedado embarazadas y no tener ningún tipo de recursos económicos ni ayuda emocional. Este cuento es una representación de la violencia ciega que ocurrió, especialmente contra las mujeres andinas de cualquier edad. Sólo al final del cuento nos enteramos que la protagonista es una niña de trece años. Jelke Boesten explica en su libro Violencia sexual en la guerra y en la paz. Género, poder y justicia posconflicto en el Perú (2016) que la violación es una reproducción de las jerarquías que ya existen en la sociedad y confirman la dominación (55). Por eso, se puede implicar que una motivación para la violación era la dominación exacerbada masculina de los cuerpos de las mujeres. Esta situación representa las dificultades continuas de esta población, pues se ve que las mujeres indígenas de todas las edades fueron las más vulnerables a torturas y violaciones sexuales, a pesar de la improbable posibilidad de su participación política. Aunque "Caminos» es una obra de ficción, las situaciones que Navarro describe se basan en la realidad recogida en testimonios. Durante el periodo del conflicto interno armado, las jóvenes fueron violadas por los dos actores del conflicto, pero $83 \%$ de las violaciones reportadas fueron cometidas por miembros de las FFAA (56). El Informe final de la CVR reporta que las víctimas de las violaciones sexuales eran reacias a compartir sus historias porque tenían vergüenza. Por eso, se infiere que las historias de muchas mujeres todavía no están registradas. "Caminos» es un cuento que hace visible las injusticias que sufrieron las jóvenes y da luz a hechos reales que se quieren borrar del imaginario nacional.

Estos cuentos visibilizan la triste situación de la población más vulnerable del post-conflicto: los niños huérfanos indígenas quienes quedan totalmente desamparados y desplazados.

Nataly Villena y Julia Wong se encargan de contarnos la experiencia de muchas mujeres jóvenes que tuvieron que huir o que fueron desplazadas forzosamente de sus ciudades natales. Ambas protagonistas, a causa del conflicto interno armado, no tienen otra opción que, primero emigrar a la capital, Lima, y finalmente intentan reubicarse en el extranjero.

En el cuento «La etapa del nido,» Nataly Villena narra la historia de una niña huantina que debido a la guerra y destrucción de su hogar por las bombas se ve obligada a emigrar junto con su familia a Lima. Sin embargo, ya de joven decide trasladarse a París para rehacer su vida. Por la calidad del trabajo que desempeña en Paris en una casa editorial, tiene que entablar relaciones con una mujer ex-senderista. El encuentro entre las dos mujeres crea un cambio positivo en la percepción que tenía la protagonista de este tipo de actor social. Pues, al conocerla puede darse cuenta que el encuentro le permite vislumbrar otro acercamiento a los hechos del pasado, y, de ese modo hacer las paces con una difícil historia personal. En el cuento, Villena muestra la transición por la que pasa la protagonista hasta el momento que se siente liberada de su pasado y acoge su presente; logrando así insertarse en su nuevo espacio y optar por quedarse allí y formar una familia.

En el cuento "Algunos infortunios de la mujer con el cabello rojo,» Wong cuenta la historia de una mujer joven que migra del norte del Perú a Lima para estudiar en la Universidad Nacional Mayor de San Marcos, altamente politizada en el momento de 
su llegada. En Lima, es injustamente acusada de ser terrorista y, por lo tanto, internada en la cárcel de mujeres Santa Mónica. Al no poderle probar nada, la familia es extorsionada por los agentes del estado peruano y ella obligada a salir del país y migrar a la Argentina. Después de unos años decide volver al Perú, pero le es imposible ser parte de una sociedad quebrada que despliega una mentalidad colonial que le es difícil de asimilar. Wong, además de enfocarse en el injusto desplazamiento forzado, visibiliza la dificultad del retorno y de la reinserción de estos jóvenes al país.

Por último, la colección incluye el cuento «Voy a cantarte» de Karina Pacheco. En este cuento, Pacheco recrea la traumática historia de la vida de un niño artesano retablista de la zona andina de Ayacucho que sufre los estragos de la más cruda violencia política que le tocó vivir a toda una población. El cuento toma como punto de partida la experiencia de vida del conocido retablista ayacuchano Edilberto Jiménez Quispe y parte de la historia de un caso en particular, el de un niño asesinado en Chuschihuaycco, que existió, pero cuyo nombre se desconoce y que fue recopilado por el mismo Jiménez Quispe. El protagonista, como Jiménez Quispe, sólo puede sobrevivir la experiencia traumática de la guerra a través de su arte, de contar con sus manos las historias más despiadadas de las violencias que ocurrieron a su alrededor. La única forma con que puede conciliar el dolor y el trauma, de alguna forma, es, en su calidad de testigo, cuando viaja y recopila las historias de los múltiples sufrimientos de los miles de afectados por la guerra. Su arte recupera la memoria negada de pueblos andinos; pues el protagonista se dedica a escuchar y dibujar los testimonios de los pobladores para luego recrearlos en arcilla y finalmente inscribir la dolorosa experiencia en un retablo. Con la llegada de la violencia política, entonces, surge un cambio radical en la elaboración temática del retablo ayacuchano, un arte tradicional que por siglos practicaron los antecesores del protagonista. Los retablos modernos ya no hablan de las fiestas ni del nacimiento del niño Jesús, ahora se encargan de plasmar una memoria difícil de contar que sólo se puede lograr en un acto de amor fraternal.

Como hemos visto, para las siete narradoras, Jennifer Thorndike, Christhiane Félip Vidal, Nataly Villena, Ysa Navarro, Karina Pacheco, Claudia Salazar Jiménez y Julia Wong, escribir, desde diferentes perspectivas, sobre las memorias del post/conflicto es solidarizarse con el otro. El acto de escribir se vuelve una forma de resistir el silencio, el mismo que oculta y borra del imaginario nacional las experiencias de aquellos que vivieron el trauma de uno $\mathrm{u}$ otro flanco de la trinchera. Más aún, la publicación de Al fin de la batalla: Después del conflicto, la violencia y el terror es un intento por acabar con la indiferencia y buscar la empatía hacia ese "otro» y restituirlo al imaginario nacional. En este contexto, vale la pena volver a referirnos al planteamiento que ha hecho Margarita Saona sobre el arte visual en el que establece que «si aceptamos que parte de lo que permitió que se cometieran atrocidades con gran parte de nuestra población fue la indiferencia de sectores que no se identifican con el universo de las víctimas, las imágenes [y en este caso pensamos en los cuentos presentados] podrían ayudar a combatir esa indiferencia al exponer los hechos que han preferido ignorarse y al promover formas de mirar que permitan que nos veamos en los otros. Sin memoria social y sin identidad colectiva no puede existir comunidad» (17). En suma, para recobrar la dignidad, como sociedad heterogénea que es el Perú, es necesario abrazar todas nuestras diversidades y solidarizarnos con el dolor y sufrimiento de todas esas vidas precarias, los damnificados del conflicto interno armado, como bien nos advirtió Vallejo hace ochenta años en su poema «Masa.»

\section{Bibliografía}

Al fin de la batalla: Después del conflicto, la violencia y el terror, compiladora Ana María Vidal

Carrasco. Lima: Cocodrilo Ediciones, 2015.

Ballón, Alejandra, ed. Memorias del caso peruano de esterilización forzada. Lima: Biblioteca Nacional del Perú, 2014.

— "Introducción.» Memorias del caso peruano de esterilización forzada, compiladora Alejandra Ballón. Lima: Biblioteca Nacional del Perú, 2014. 27-43.

Boesten, Jelke. Violencia sexual en la guerra y en la paz. Género, poder y justicia posconflicto en el Perú. Trad. Rafael Drinot Silva. Lima: Biblioteca Nacional del Perú, 2016.

Butler, Judith. Cuerpos que importan. Sobre los limites materiales y discursivos del sexo. Trad. Fermín Rodríguez. Buenos Aires: Editorial Paidós, 2012.

- Vida precaria. El poder del duelo y la violencia. Trad. Fermín Rodríguez. Buenos Aires: Editorial Paidós, 2006.

EwIG, Christina. «La economía política de las esterilizaciones forzadas en el Perú.» Memorias del caso peruano de esterilización forzada, compiladora Alejandra 
Ballón. Lima: Biblioteca Nacional del Perú, 2014. 49-69.

FÉlip Vidal, Christiane. "Cuando el río suena.» Al fin de la batalla: Después del conflicto, la violencia y el terror, compiladora Ana María Vidal Carrasco. Lima: Cocodrilo Ediciones, 2015. 29-40.

Guerrero Peirano, Victoria. «Sanación.» http://www. elhablador.com/guerrero.htm Web. 16 agosto 2017.

«Informe Final.» Comisión de la Verdad y Reconciliación, 28 agosto 2003, http://www.cverdad.org.pe/. Web. 30 mayo 2017.

Navarro, Ysa. "Caminos.» Al fin de la batalla: Después del conflicto, la violencia y el terror, compiladora Ana María Vidal Carrasco. Lima: Cocodrilo Ediciones, 2015. 55-61.

Pacheco, Karina. «Voy a cantarte.» Al fin de la batalla: Después del conflicto, la violencia y el terror, compiladora Ana María Vidal Carrasco. Lima: Cocodrilo Ediciones, 2015. 63-71.

SalazAr Jiménez, Claudia. «El grito.» Al fin de la batalla: Después del conflicto, la violencia y el terror, compiladora Ana María Vidal Carrasco. Lima: Cocodrilo Ediciones, 2015. 75-81.
SaOnA, Margarita. Memory Matters in Transitional Peru. New York: Palgrave Macmillan, 2014.

Thorndike, Jennifer. «La muerte tenía nuestros dedos.» Al Fin de la Batalla..., compiladora Ana María Vidal Carrasco. Lima: Cocodrilo Ediciones, 2015. 19-28.

Ulfe, Makena. "Prólogo.» Al fin de la batalla: Después del conflicto, la violencia y el terror, compiladora Ana María Vidal Carrasco. Lima: Cocodrilo Ediciones, 2015. 11-14.

VAllejo, César. «Masa.» César Vallejo. Poemas completos. Edición de Ricardo González Vigil. Lima: Ediciones Copé, 2005. 450.

Vidal Carrasco, Ana María. "Pero el cadáver ¡Ay! siguió muriendo.» Al fin de la batalla: Después del conflicto, la violencia y el terror, compiladora Ana María Vidal Carrasco. Lima: Cocodrilo Ediciones, 2015. 9-10.

Villena, Nataly. "La etapa del nido.» Al fin de la batalla: Después del conflicto, la violencia y el terror, compiladora Ana María Vidal Carrasco. Lima: Cocodrilo Ediciones, 2015. 41-54.

Wong, Julia. «Algunos infortunios de la mujer con el caballo rojo.» Al fin de la batalla: Después del conflicto, la violencia y el terror, compiladora Ana María Vidal Carrasco. Lima: Cocodrilo Ediciones, 2015. 83-100. 